\title{
AEROMAGNETIC MAP OF THE SPRING HILL QUADRANGLE TOLLAND AND WINDHAM COUNTIES, CONNECTICUT
}

By

P. W. Philbin and C. W. Smith

\section{GEOPHYSICAL INVESTIGATIONS}

MAP GP-585

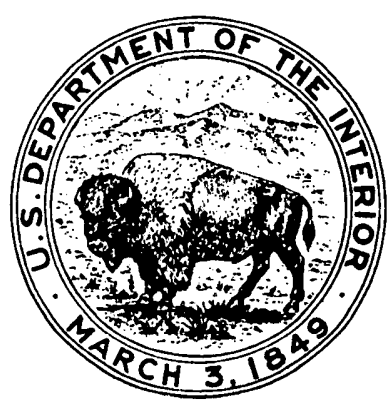

